\title{
Bovine pericardial versus porcine stented replacement mitral valves: early hemodynamic performance and clinical results of a randomized comparison of the Perimount and the Mosaic valves
}

\author{
Bo Fu ${ }^{1,2 \#}$, Xiankun Liu ${ }^{1,2 \#}$, Runsheng Wei ${ }^{1,2 \#}$, Qingliang Chen ${ }^{1}$, Zhigang Guo ${ }^{1}$, Nan Jiang ${ }^{1}$ \\ ${ }^{1}$ Department of Cardiovascular Surgery, Tianjin Chest Hospital, Tianjin, China; ${ }^{2}$ Tianjin Medical University, Tianjin, China \\ Contributions: (I) Conception and design: B Fu, N Jiang; (II) Administrative support: N Jiang; (III) Provision of study materials or patients: B Fu, Q \\ Chen; (IV) Collection and assembly of data: X Liu, R Wei; (V) Data analysis and interpretation: Z Guo; (VI) Manuscript writing: All authors; (VII) \\ Final approval of manuscript: All authors. \\ "These authors contributed equally to this work. \\ Correspondence to: Prof. Nan Jiang, MD; Prof. Zhigang Guo, MD. Department of Cardiovascular Surgery, Tianjin Chest Hospital, No.261, South \\ Taierzhuang road, Tianjin 300051, China. Email: tjxkcs2@163.com; Zhigangguo@yahoo.com.
}

Background: To compare the hemodynamic and clinical outcomes following mitral valve replacement with the Perimount valve with those of the Mosaic valve.

Methods: A total of 145 consecutive patients with rheumatic heart valve disease who underwent single bioprosthetic mitral valve replacement were randomized to receive either the Perimount $(n=72)$ valve or the Mosaic bioprosthesis ( $\mathrm{n}=73$ ). The mean age of patients was 72.1 years (range, 58-89 years) with a sex distribution of $55.2 \%$ female and $44.8 \%$ male. Patients underwent follow up transthoracic echocardiography at 3 months and 1 year postoperatively. We compared demographics, preoperative clinical data, operative data, hemodynamic profiles, and clinical outcomes.

Results: The cross-clamp time was similar, with $50.7 \pm 15.3$ minutes for the Perimount and $50.7 \pm 21.8$ minutes for the Mosaic bioprosthesis. The total bypass time was also similar, with $91.3 \pm 25.7$ minutes for the Perimount and $87.8 \pm 25.6$ minutes for the Mosaic valve. The peak and mean pressure gradients were lower in the Perimount group for all valve sizes and the difference was statistically significant at 1 year. The effective orifice area (EOA) was slightly larger in the Perimount valve $\left(1.98 \pm 0.21 v s .1 .89 \pm 0.71 \mathrm{~cm}^{2}, \mathrm{P}=0.538\right)$ postoperatively, but there was no significant difference at 1 year. There were no differences in preoperative or postoperative left atrium diameter (LAD), left ventricular diastolic diameter (LVDD), left ventricular systolic diameter (LVSD), left ventricular ejection fraction (LVEF), pulmonary artery pressure (PAP). The mortality and major complications rate were similar between the two groups.

Conclusions: The Perimount prostheses is superior to the Mosaic prostheses after mitral valve replacement, achieving statistically significant lower gradients and larger EOA when compared on the basis of manufacturer-labeled valve sizes. Both valves appear to provide satisfactory clinical results.

Keywords: Bioprosthetic valve; mitral valve replacement; hemodynamic

Submitted Oct 12, 2020. Accepted for publication Dec 08, 2020.

doi: $10.21037 /$ jtd-20-3274

View this article at: http://dx.doi.org/10.21037/jtd-20-3274 


\section{Introduction}

In comparison to mechanical prostheses, bioprosthetic valves avoid many of the major thrombotic and hemorrhagic complications associated with long-term anticoagulation (1). Most bioprostheses are made of either bovine pericardium (such as Carpentier Edwards Perimount, Carpentier Edwards Perimount Magna, and Sorin Soprano) or porcine heart valve tissue (such as Medtronic Mosaic, Medtronic Mosaic Ultra, St Jude Medical Epic Supra) (2). Whilst both have been shown to warrant satisfactory hemodynamic results and tissue durability for 10 to 15 years, there is a perception that pericardial valves have better hemodynamic function (3-6). Pericardial prostheses are credited to have a favorable hemodynamic profile compared with porcine valves. However, the impact of improved postoperative transvalvular gradients on outcome is still a matter of debate. Although some studies have reviewed bioprosthetic replacement of the aortic valve (7), few have compared the hemodynamic and clinical outcomes between Perimount and Mosaic bioprostheses for mitral valve replacement. We designed a randomized trial to compare patients undergoing mitral valve replacement for rheumatic heart disease with the Medtronic Mosaic porcine valve (Medtronic, Inc., St. Paul, MN, USA) and those receiving the CarpentierEdwards Perimount bovine pericardial valve (Edwards Lifesciences, Irvine, Calif). The primary objective of the study was to compare the hemodynamics associated with each type of valve. Secondary end points were major complication rates and measures of overall health in the first year after surgery. We present the following article in accordance with the CONSORT reporting checklist (available at http://dx.doi.org/10.21037/jtd-20-3274).

\section{Methods}

\section{Patients}

Between January 2014 and February 2015, a total of 145 consecutive patients with rheumatic heart valve disease undergoing single bioprosthetic mitral valve replacement were randomized to receive either the Perimount or the Mosaic valve. Patients undergoing an isolated mitral valve replacement and requiring associated coronary artery bypass grafting, COX-maze IV, or tricuspid annuloplasty were included in the study. Excluded from the study were those receiving more than one valve at the time of surgery and those with a pre-existing prosthetic valve in another position.
The mean age of patients was 72.1 years (range, $58-89$ years) and $55.2 \%(80 / 145)$ were female. The study was conducted in accordance with the Declaration of Helsinki (as revised in 2013). The study was approved by the ethics committee of Tianjin Chest Hospital (No.IRBSOP-016(F)-001-01) and informed consent was taken from all individual participants. The study compared demographics, preoperative clinical data, operative data, hemodynamic profiles, and clinical outcomes.

\section{Randomization}

The randomization of patients was computer generated and a note specifying either valve was placed into a sealed envelope to allow for consecutive intraoperative allocation, subject to patient eligibility. Whilst patients were randomized to receive either the Perimount valve or the Mosaic valve, procedural difficulties caused two patients randomized to receive a Perimount valve, receive a Mosaic valve, and one randomized to receive a Mosaic valve, receive a Perimount. Of the 145 patients, 72 patients were implanted with the Perimount and 73 with the Mosaic valve.

\section{Surgery}

Mitral valve replacement was undertaken using standard cardiopulmonary bypass at mild hypothermia with cold crystalloid cardioplegia. The posterior leaflet chordae tendineae and its sub-valvular tissues were left intact to the degree possible. The manufacturer's labeled valve size has no standard, so any comparison of valve performance requires uniform measurements of valve size. The annular diameter was assessed based on manual measurements using standardized metric sizers (graduated in millimeters). Thereafter, sizing for both valve types was undertaken in each patient using the appropriate original sizer provided by each manufacturer before the randomization envelope was opened. Both valves were implanted according to the manufacturer's instructions. The selected prostheses size was determined by the largest sizers whose lower cylindrical portion comfortably fitted into the patient annulus. Each bioprostheses were implanted with pledget-supported, interrupted, non-everting mattress sutures.

\section{Follow up}

After discharge, patients were interviewed at 3 months 
Table 1 Demographic data

\begin{tabular}{lccc}
\hline Characteristics & Perimount & Mosaic & P value \\
\hline $\mathrm{N}$ & 72 & 73 & \\
Female & $39(54.2 \%)$ & $41(56.1 \%)$ & 0.852 \\
Age (y) & $72.6 \pm 5.1$ & $71.5 \pm 7.4$ & 0.298 \\
Rheumatic mitral valve lesion & & \\
MS & $32(44.4 \%)$ & $32(43.8 \%)$ & \\
MR & $27(37.5 \%)$ & $27(37.0 \%)$ & \\
Mixed & $13(18.1 \%)$ & $14(19.2 \%)$ & \\
BMI (kg·m $\left.{ }^{-2}\right)$ & $23.6 \pm 3.8$ & $23.4 \pm 3.6$ & 0.922 \\
Hypotension & $30(41.7 \%)$ & $26(35.6 \%)$ & \\
Diabetes & $11(15.3 \%)$ & $7(9.6 \%)$ & \\
Atrial fibrillation & $32(44.4 \%)$ & $30(41.1 \%)$ & \\
NYHA classification & & & \\
Class I & 0 & 0 \\
Class II & $15(20.8 \%)$ & $17(23.3 \%)$ & \\
Class III & $50(69.4 \%)$ & $49(67.1 \%)$ & \\
Class IV & $79.7 \%)$ & $7(9.6 \%)$ & \\
\hline
\end{tabular}

$t$ test for independent samples. MS, mitral valve stenosis; MR, mitral valve regurgitation; BMI, body mass index. NYHA, New York Heart Association.

and at 1 year postoperatively. All patients initially received subcutaneous heparin which was suspended after extubation (8), at which point, oral anticoagulation was commenced to reach a target international normalized ratio of 1.5 to 2.5 (9). Oral anticoagulants were maintained indefinitely in patients with atrial fibrillation and were replaced with aspirin (100 $\mathrm{mg}$ per day) after 3 months in patients with sinus rhythm.

\section{Echocardiography}

Patients underwent transthoracic echocardiography (Philips iE33, Philips, Andover, MA, USA), at 3 months and 1 year postoperatively. Measurements were made according to the recommendations of the American Society of Echocardiography (10) over 3 cycles in sinus rhythm or over 6 cycles in atrial fibrillation. The modified Bernoulli equation was used to calculate peak and mean pressure gradients across the prosthetic valve and the effective orifice area (EOA) was calculated by the continuity equation (11).

\section{Clinical events}

The definitions used were those recommended by the guidelines of The Society of Thoracic Surgeons and The American Association for Thoracic Surgery (10). Early events were classified as occurring in the first 30 days and late events between 30 days and 12 months.

\section{Statistical analysis}

Statistical analysis was performed using SPSS software version 18 (SPSS Inc., Chicago, IL, USA). Continuous variables were shown as mean $\pm \mathrm{SD}$ and categorical variables presented as simple percentages. Quantitative data were compared using the Student- $t$ test. Associations among categorical variables were compared by Pearson's Chi-square test or Fisher's exact test as appropriate. Overall survival and freedom from major prosthesis-related complications were calculated with the Kaplan-Meier method and statistical significance was defined as $\mathrm{P}<0.05$. As there were few patients in the size 25 group, statistical comparison was not performed for this group.

\section{Results}

A total of 145 consecutive patients selected for elective bioprosthetic mitral valve replacement were prospectively assigned to receive either the Perimount or Mosaic. The comparative statistical analysis of patient characteristics revealed a similarity of ages between the Perimount and Mosaic groups (72.6 \pm 5.1 vs. $71.5 \pm 7.4$ years) respectively. The percentage of patients with comorbidities, such as hypertension, diabetes, atrial fibrillation, NYHA class (mainly at class III-IV), were analogous without significant difference (Table 1).

The history of concomitant surgeries and the manufacture's valve size were similar in both groups. The cross-clamp time was also similar, with $50.7 \pm 15.3$ minutes for the Perimount and 50.7 \pm 21.8 minutes for the Mosaic valve, as was the total bypass time with $91.3 \pm 25.7$ minutes for the Perimount and $87.8 \pm 25.6$ minutes for the Mosaic valve (Table 2).

Hemodynamic comparisons between the two groups according to valve size are listed in Table 3. Peak and mean pressure gradients were lower in the Perimount group overall and for each valve size and the difference was statistically significant at the first year. The EOA was slightly larger in the Perimount valve postoperatively, but there was no significant difference at the first year. 
Table 2 Operative data

\begin{tabular}{lccc}
\hline Characteristics & Perimount $n=72$ & Mosaic $n=73$ & P value \\
\hline Valve size & 1 & 2 & \\
25 & 49 & 47 & \\
27 & 22 & 24 & \\
29 & $27.6 \pm 0.12$ & $27.6 \pm 0.12$ & 0.970 \\
Average & & & \\
Concomitant & $20(27.8 \%)$ & $22(30.1 \%)$ & \\
CABG & $12(16.7 \%)$ & $19(26.0 \%)$ & \\
Maze & $19(26.4 \%)$ & $14(19.2 \%)$ & \\
TVP & $91.27 \pm 25.65$ & $87.82 \pm 25.62$ & 0.761 \\
CPB time (min) & $50.73 \pm 15.30$ & $50.72 \pm 21.82$ & 0.999 \\
Aortic cross-clamp (min) & & & \\
\hline
\end{tabular}

CABG, coronary artery bypass grafting; TVP, tricuspid valvuplasty; CPB, Cardiopulmonary bypass.

Table 3 Hemodynamic results at 1 year postoperative according to valve size

\begin{tabular}{|c|c|c|c|}
\hline Valve size & Perimount & Mosaic & $P$ value \\
\hline \multicolumn{4}{|l|}{ All } \\
\hline PG (mmHg) & $12.02 \pm 3.04$ & $18.25 \pm 4.43$ & 0.000 \\
\hline $\mathrm{MG}(\mathrm{mmHg})$ & $4.81 \pm 1.22$ & $6.24 \pm 1.21$ & 0.000 \\
\hline $\mathrm{PV}(\mathrm{m} / \mathrm{s})$ & $1.76 \pm 0.17$ & $2.14 \pm 0.24$ & 0.000 \\
\hline $\mathrm{EOA}\left(\mathrm{cm}^{2}\right)$ & $1.98 \pm 0.21$ & $1.89 \pm 0.71$ & 0.538 \\
\hline \multicolumn{4}{|l|}{27} \\
\hline$P G(m m H g)$ & $13.17 \pm 3.04$ & $19.35 \pm 4.31$ & 0.000 \\
\hline $\mathrm{MG}(\mathrm{mmHg})$ & $5.31 \pm 1.23$ & $6.79 \pm 1.22$ & 0.000 \\
\hline $\mathrm{PV}(\mathrm{m} / \mathrm{s})$ & $1.82 \pm 0.17$ & $2.29 \pm 0.30$ & 0.000 \\
\hline $\mathrm{EOA}\left(\mathrm{cm}^{2}\right)$ & $1.90 \pm 0.25$ & $1.83 \pm 0.32$ & 0.531 \\
\hline \multicolumn{4}{|l|}{29} \\
\hline PG (mmHg) & $10.87 \pm 3.03$ & $17.15 \pm 4.57$ & 0.000 \\
\hline $\mathrm{MG}(\mathrm{mmHg})$ & $4.31 \pm 1.21$ & $5.69 \pm 1.18$ & 0.000 \\
\hline $\mathrm{PV}(\mathrm{m} / \mathrm{s})$ & $1.70 \pm 0.17$ & $1.99 \pm 0.17$ & 0.000 \\
\hline $\mathrm{EOA}\left(\mathrm{cm}^{2}\right)$ & $2.08 \pm 0.15$ & $1.95 \pm 0.39$ & 0.655 \\
\hline
\end{tabular}

PG, peak pressure gradients; MG, mean pressure gradients; PV, peak velocity; EOA, effective orifice area.
Table 4 Major postoperative complications

\begin{tabular}{lccc}
\hline Characteristics & Perimount & Mosaic & P value \\
\hline Thromboembolism & $1(1.7 \%)$ & $1(1.8 \%)$ & 1.000 \\
Hemorrhage & $1(1.7 \%)$ & $1(1.8 \%)$ & 1.000 \\
Endocarditis & 0 & $1(1.8 \%)$ & 0.496 \\
Perivalvular leakage & $1(1.7 \%)$ & $1(1.8 \%)$ & 1.000 \\
\hline
\end{tabular}

Hemodynamic differences were also apparent in the valves when compared by label size.

The sequential echocardiographic measurements left atrium diameter (LAD), left ventricular diastolic diameter (LVDD), left ventricular systolic diameter (LVSD), left ventricular ejection fraction (LVEF) and pulmonary artery pressure (PAP) were taken on the day of surgery, at 3 months, and 1year post-surgery to evaluate bioprosthetic function. The results show that LAD, LVDD, LVSD, and PAP decreased postoperatively indicating both bioprosthetic valves could effectively relieve the severity of mitral function. In addition, although there were significant differences in hemodynamic results at the 3 months and 1 year follow up between the two groups, the extent of postoperative reduction was equivalent with relative consistency. LVEF dropped after surgery in both groups, improving with better postoperatively at 1 year. These findings were not statistically significant differences compared to the patients in the both group at 1 year (Table 4, Figure 1).

There were no statistically significant differences in mortality and major postoperative complication between the two groups. One early death (within 30 days) occurred in the Perimount group and one in the Mosaic group. There were three late deaths (between 30 days and 12 months) in the Perimount group and four in the Mosaic group (Figure 2). Thromboembolism occurred once in each group, as did a hemorrhage event. There were no cases of endocarditis in the Perimount group and one case in the Mosaic group, and both groups recorded one case of trivial perivalvular leakage (Figure 3, Table 5).

\section{Discussion}

Previous studies comparing porcine and bovine valves 

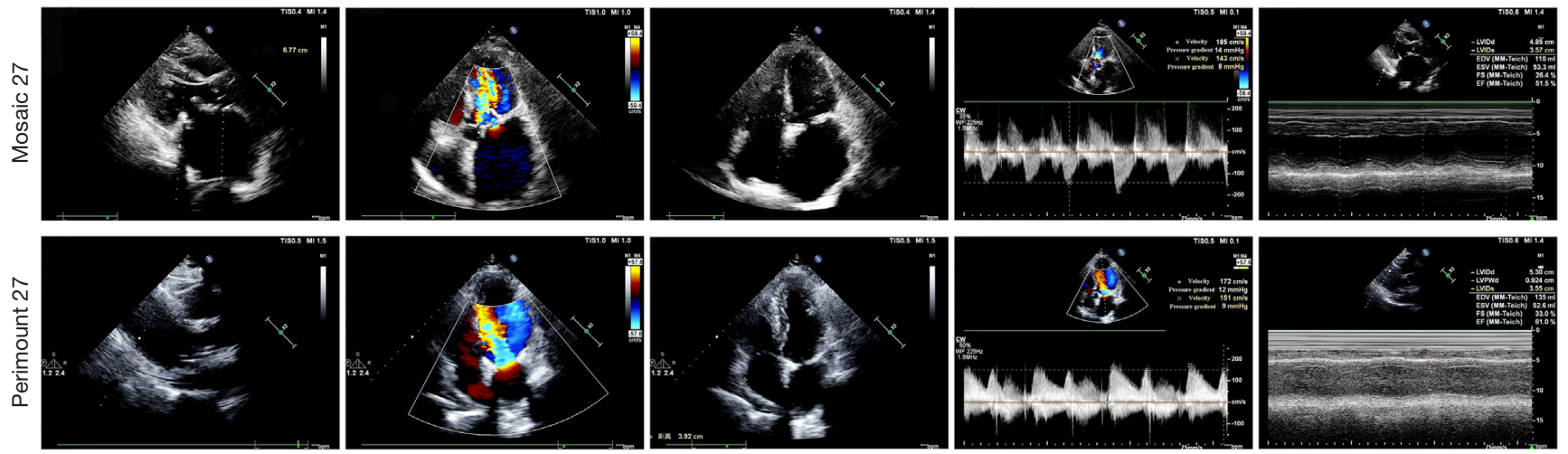

Figure 1 Transthoracic echocardiography: mitral valve replacement by the $27 \mathrm{~mm}$ Mosaic, mitral valve peak velocity is $1.43 \mathrm{~m} / \mathrm{s}$, mean pressure gradient is $8 \mathrm{mmHg}$, LVEF is $51.5 \%$; mitral valve replacement by the $27 \mathrm{~mm}$ Perimount, mitral valve peak velocity is $1.51 \mathrm{~m} / \mathrm{s}$, mean pressure gradient is $9 \mathrm{mmHg}$, LVEF is $61.0 \%$.

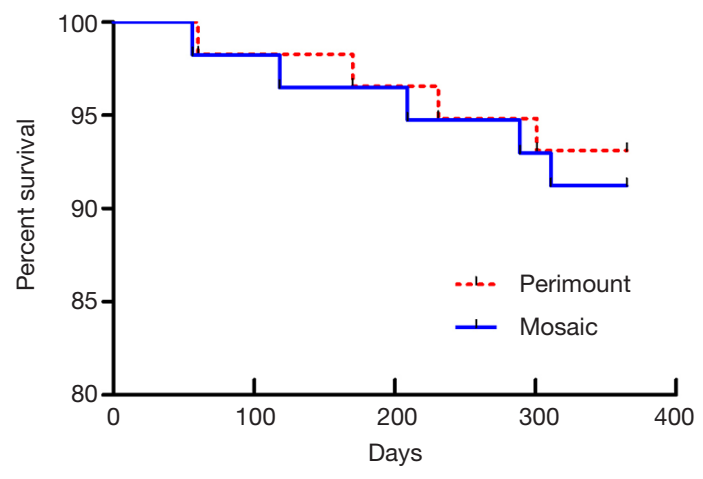

Figure 2 Kaplan-Meier estimated unadjusted survival after mitral valve replacement with a Perimount or Mosaic bioprostheses. $\mathrm{P}=0.1386$.

have focused on aortic valve replacement. At this location, both types of valves show comparable results in mortality, postoperative functional status, and valve durability, but the bovine valve is superior in its complication and haemodynamic profile. Unlike Europe or North America, chronic rheumatic valvular disease is the most common heart valve disease in China, and mitral stenosis is the most frequent pathological pattern (12). However, until now, few studies have compared differences in hemodynamics and clinical outcomes among bioprostheses implanted in the mitral position.

The results of this randomized study suggest better hemodynamic function is found with the Perimount valve in comparison to the Mosaic valve. The postoperative peak and mean pressure gradients were statistically lower with

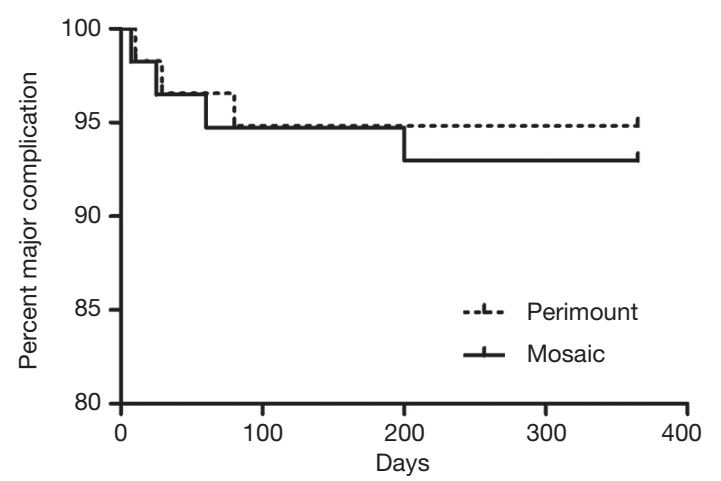

Figure 3 Kaplan-Meier estimated major complications after mitral valve replacement with a Perimount or Mosaic bioprostheses. $\mathrm{P}=0.6806$.

the Perimount group, although at one year this difference was relatively small; about $2 \mathrm{mmHg}$ in the mean and $4 \mathrm{mmHg}$ in the peak pressure. When the comparison was made by labeled valve sizes, our data clearly showed that the Perimount prosthesis had a hemodynamic advantage, especially in valve sizes 27 and $29 \mathrm{~mm}$. In general, the inner diameter of the Perimount prosthesis is larger across all sizes than that of the Mosaic prosthesis, whereas the external sewing ring diameter of the Mosaic valve is $2 \mathrm{~mm}$ larger in size 25 and $3 \mathrm{~mm}$ larger in sizes 27 and 29 in comparison to the Mosaic valve (13).

Unlike implanting bioprosthetic valves for aortic valve replacement, the current study demonstrated the resultant hemodynamic advantages of the Perimount bioprostheses which show lower mean pressure gradients and larger 
Table 5 Echocardiography results at 1 year postoperative according to valve size

\begin{tabular}{|c|c|c|c|}
\hline Characteristics & Perimount & Mosaic & $P$ value \\
\hline \multicolumn{4}{|l|}{ LAD (mm) } \\
\hline Pre & $52.00 \pm 10.66$ & $52.34 \pm 8.97$ & 0.886 \\
\hline Post 3 month & $44.08 \pm 6.98$ & $42.65 \pm 5.16$ & 0.441 \\
\hline Post 1 year & $43.56 \pm 8.42$ & $45.78 \pm 8.23$ & 0.291 \\
\hline \multicolumn{4}{|l|}{ LVDD (mm) } \\
\hline Pre & $53.05 \pm 8.34$ & $53.56 \pm 8.09$ & 0.799 \\
\hline Post 3 month & $49.64 \pm 5.16$ & $50.35 \pm 5.17$ & 0.631 \\
\hline Post 1 year & $49.59 \pm 4.96$ & $50.45 \pm 6.08$ & 0.541 \\
\hline \multicolumn{4}{|l|}{ LVSD (mm) } \\
\hline Pre & $35.53 \pm 7.21$ & $36.09 \pm 5.81$ & 0.694 \\
\hline Post 3 month & $34.85 \pm 5.30$ & $33.88 \pm 5.30$ & 0.519 \\
\hline Post 1 year & $34.66 \pm 4.99$ & $33.68 \pm 4.45$ & 0.415 \\
\hline \multicolumn{4}{|l|}{ LVEF (\%) } \\
\hline Pre & $57.86 \pm 6.78$ & $60.63 \pm 6.77$ & 0.048 \\
\hline Post 3 month & $56.21 \pm 6.48$ & $56.53 \pm 7.42$ & 0.501 \\
\hline Post 1 year & $57.38 \pm 6.36$ & $58.78 \pm 6.34$ & 0.379 \\
\hline \multicolumn{4}{|l|}{ PAP (mmHg) } \\
\hline Pre & $45.25 \pm 12.00$ & $46.84 \pm 13.60$ & 0.536 \\
\hline Post 3 month & $35.82 \pm 5.67$ & $36.06 \pm 4.44$ & 0.875 \\
\hline Post 1 year & $33.38 \pm 4.48$ & $38.31 \pm 8.90$ & 0.007 \\
\hline
\end{tabular}

Values are mean $\pm S D$; $P$ value was showed when tricuspid and bicuspid groups were compared by unpaired $t$-test. LAD, left atrium diameter; LVDD, left ventricular diastolic diameter; LVSD, left ventricular systolic diameter; LVEF, left ventricular ejection fraction; PAP, pulmonary artery pressure.

EOA. These findings correlate closely with those reported by other researchers using these bioprostheses $(14,15)$ and confirmed the observed hemodynamic superiority of the Perimount prosthesis in the small aortic annulus (16) and under stress conditions (17). It must be emphasized, our study showed low transprosthetic gradients and adequate EOA, compare favorably with results reported previously (18-20). In addition, our results indicate satisfactory performance of the bioprostheses in the mitral position, which is indirectly confirmed by clinical improvement at one-year follow-up.

The focus of previous research has been the objective assessment of hemodynamic function and clinical event rates including mortality and morbidity. The ability of patients to exercise and their quality of life is also of concern. The minor hemodynamic difference between the two valves seen in our study did not translate to any difference in mortality and morbidity, and both groups had large and clinically significant improvements compared with preoperative levels. In particular, the devices in this study have shown low mean pressure gradients, large EOAs, and high freedom rates from device-related adverse events.

We found no difference in regression of LA, LVDD, LVSD and PAP at the 1 year follow up. It is possible that valves with a larger EOA will allow patients to avoid symptoms for longer as progressive stenosis develops because of primary valve failure. This could reduce the risk of cardiac events and reoperation in the long term.

\section{Limitations}

The study has several limitations. Firstly, the overall population sizes were small, limiting definitive conclusions to be drawn. Secondly, this study reports information to only 1 year and it is possible that late event rates or durability may differ over a longer duration. It is our intention to follow up on patients at 5 years. Finally, it is also possible that the hemodynamic differences might have been greater if we had used the Carpentier-Edwards Perimount Magna valve (Edwards Lifesciences, Irvine, Calif), which is a wholly supra-annular version of the Perimount design.

\section{Conclusions}

This study demonstrates that the hemodynamic outcomes of the Perimount bioprosthetic valve are better than those of the Mosaic prostheses after mitral valve replacement, by achieving lower gradients and larger EOA when a comparison on the basis of manufacturer-labeled valve sizes is made. Both valves appear to provide satisfactory clinical results.

\section{Acknowledgments}

Funding: The National Key Research and Development Program of China (grant number 2020YFC2008100).

\section{Footnote}

Reporting Checklist: The authors have completed the 
CONSORT reporting checklist. Available at http://dx.doi. org/10.21037/jtd-20-3274

Data Sharing Statement: Available at http://dx.doi. org/10.21037/jtd-20-3274

Conflicts of Interest: All authors have completed the ICMJE uniform disclosure form (available at http://dx.doi. org/10.21037/jtd-20-3274). The authors have no conflicts of interest to declare.

Ethical Statement: The authors are accountable for all aspects of the work in ensuring that questions related to the accuracy or integrity of any part of the work are appropriately investigated and resolved. The study was conducted in accordance with the Declaration of Helsinki (as revised in 2013). The study was approved by the ethics committee of Tianjin Chest Hospital (No.IRB-SOP016(F)-001-01) and informed consent was taken from all individual participants.

Open Access Statement: This is an Open Access article distributed in accordance with the Creative Commons Attribution-NonCommercial-NoDerivs 4.0 International License (CC BY-NC-ND 4.0), which permits the noncommercial replication and distribution of the article with the strict proviso that no changes or edits are made and the original work is properly cited (including links to both the formal publication through the relevant DOI and the license). See: https://creativecommons.org/licenses/by-nc-nd/4.0/.

\section{References}

1. Head SJ, Celik M, Kappetein AP. Mechanical versus bioprosthetic aortic valve replacement. Eur Heart J 2017;38:2183-91.

2. Alnasser S, Cheema AN, Simonato M, et al. Matched Comparison of Self-Expanding Transcatheter Heart Valves for the Treatment of Failed Aortic Surgical Bioprosthesis: Insights From the Valve-in-Valve International Data Registry (VIVID). Circ Cardiovasc Interv 2017;10:e004392.

3. Bove EL, Marvasti MA, Potts JL, et al. Rest and exercise hemodynamics following aortic valve replacement. A comparison between 19 and $21 \mathrm{~mm}$ Ionescu-Shiley pericardial and Carpentier-Edwards porcine valves. J Thorac Cardiovasc Surg 1985;90:750-5.

4. Gonzalez-Juanatey JR, Garcia-Bengoechea JB, Vega M, et al. Echocardiographic features of the normofunctional Labcor-Santiago pericardial bioprosthesis. J Heart Valve Dis 1994;3:548-55.

5. Grunkemeier GL, Furnary AP, Wu Y, et al. Durability of pericardial versus porcine bioprosthetic heart valves. J Thorac Cardiovasc Surg 2012;144:1381-6.

6. Chambers JB, Rajani R, Parkin D, et al. Bovine pericardial versus porcine stented replacement aortic valves: early results of a randomized comparison of the Perimount and the Mosaic valves. J Thorac Cardiovasc Surg 2008;136:1142-8.

7. Glaser N, Franco-Cereceda A, Sartipy U. Late survival after aortic valve replacement with the perimount versus the mosaic bioprosthesis. Ann Thorac Surg 2014;97:1314-20.

8. Borghi C, Paolillo S, Cicero AF, et al. New oral anticoagulants and prevention of thromboembolic events in patients with hypertension and atrial fibrillation: an appraisal. J Hypertens 2017;35:689-95.

9. Fu B, Chen H, Dong L. Antithrombotic and thrombolytic therapy for valvular disease: can this guideline apply to Chinese? Chest 2013;143:1513-4.

10. Akins CW, Miller DC, Turina MI, et al. Guidelines for reporting mortality and morbidity after cardiac valve interventions. J Thorac Cardiovasc Surg 2008;135:732-8.

11. Stewart SF, Nast EP, Arabia FA, et al. Errors in pressure gradient measurement by continuous wave Doppler ultrasound: type, size and age effects in bioprosthetic aortic valves. J Am Coll Cardiol 1991;18:769-79.

12. Nkomo VT, Gardin JM, Skelton TN, et al. Burden of valvular heart diseases: a population-based study. Lancet 2006;368:1005-11.

13. Jamieson WR, Janusz MT, MacNab J, et al. Hemodynamic comparison of second- and third-generation stented bioprostheses in aortic valve replacement. Ann Thorac Surg 2001;71:S282-4.

14. Seitelberger R, Bialy J, Gottardi R, et al. Relation between size of prosthesis and valve gradient: comparison of two aortic bioprosthesis. Eur J Cardiothorac Surg 2004;25:358-63.

15. Tasca G, Brunelli F, Cirillo M, et al. Mass regression in aortic stenosis after valve replacement with small size pericardial bioprosthesis. Ann Thorac Surg 2003;76:1107-13.

16. Gerosa G, Tarzia V, Rizzoli G, et al. Small aortic annulus: the hydrodynamic performances of 5 commercially available tissue valves. J Thorac Cardiovasc Surg 2006;131:1058-64. 
17. Eichinger WB, Botzenhardt F, Keithahn A, et al. Exercise hemodynamics of bovine versus porcine bioprostheses: a prospective randomized comparison of the mosaic and perimount aortic valves. J Thorac Cardiovasc Surg 2005;129:1056-63.

18. Riess FC, Cramer E, Hansen L, et al. Clinical results of the Medtronic Mosaic porcine bioprosthesis up to 13 years. Eur J Cardiothorac Surg 2010;37:145-53.

Cite this article as: Fu B, Liu X, Wei R, Chen Q, Guo Z, Jiang $\mathrm{N}$. Bovine pericardial versus porcine stented replacement mitral valves: early hemodynamic performance and clinical results of a randomized comparison of the Perimount and the Mosaic valves. J Thorac Dis 2021;13(1):262-269. doi: 10.21037/jtd-203274
19. Polo ML, Legarra JJ, Vilar M, et al. Early calcification of a Carpentier-Edwards Perimount mitral valve in an elderly woman. J Thorac Cardiovasc Surg. 2002;124:1043-4.

20. Weber PA, Jouan J, Matsunaga A, et al. Evidence of mitigated calcification of the Mosaic versus Hancock Standard valve xenograft in the mitral position of young sheep. J Thorac Cardiovasc Surg 2006;132:1137-43. 